\title{
Guarda compartilhada: aspectos teóricos
}

\author{
Shared custody famyly relationship
}

\author{
Ana Flávia Cunha de Lima* \\ Solange Aparecida Serrano**
}

\begin{abstract}
Resumo:
No dia 13/06/2008 foi aprovado o projeto de lei que institui no Código Civil, a guarda compartilhada dos filhos, em caso de separação dos pais. O objetivo desta legislação é a preservação dos laços entre pais e filhos e seguridade às crianças e adolescentes do direito à convivência familiar. $O$ presente trabalho, através de estudos das teorias já existentes e análise de legislações pertinentes, apresenta sucintas comparações teóricas e tece considerações acerca do que prescreve a "lei da guarda compartilhada", relacionando-a com o que pressupõe o Estatuto da Criança e do Adolescente (ECA) quanto ao direito à convivência familiar; quanto aos deveres inerentes ao exercício do poder familiar e, ainda, quanto à obrigação da família de promover o bem estar da criança.
\end{abstract}

Palavras-chave: Separação Conjugal; Filhos; Guarda Compartilhada; Convivência Familiar; Poder Familiar.

\begin{abstract}
:
On 06/13/2008, was approved the bill establishing the Civil Code, the shared custody of the children in the event of divorce from parents. The purpose of this legislation is to preserve the bonds between parents and children and safety for children and adolescents, the right to family life. This work, through studies of existing theories and analysis of relevant laws, presents brief theoretical comparisons and considers about prescribing the "law of shared custody, relating it to what it implies to the Estatuto da Criança e do Adolescente (ECA), for the right to family life, as to the duties inherent in the exercise of family power and also on the family's obligation to promote the well being of children.
\end{abstract}

Key words: Divorce; Children; Adolescent; Shared custody; Family power.

\footnotetext{
* Assistente Social, Especialista em Intervenção Familiar. Especialista em Violência Doméstica; Assistente Social Judicial do Tribunal de Justiça-MG. . (E-mail anacunhalima@hotmail.com)

** Psicóloga, Doutora em Psicologia pela Universidade de São Paulo (USP). Especialista em Violência Doméstica pela USP e em Desenvolvimento em Pediatria pela Universidade Estadual de Campinas (UNICAMP); Docente do curso de Pós-Graduação em Intervenção Familiar (Unifran). Atua como Psicóloga Judiciária do Tribunal de Justiça (Comarca de Ribeirão Preto/SP). Serrano. (E-mail: solserrano@ibest.com.br)
} 


\section{Introdução}

No dia 13 de junho de 2008 foi sancionada pelo Presidente da República, Luís Inácio Lula da Silva, a Lei № 11.698/2008, que dispõe sobre o instituto da guarda compartilhada, para respaldar as decisões judiciais nas Varas de Família.

Essa lei promoveu alterações nos artigos 1.583 e 1.584 da Lei № 10.406/2002, instituindo a guarda compartilhada. Assim, no Código Civil passa a valer:

\footnotetext{
Art. 1.583. A guarda será unilateral ou compartilhada.§ $1^{\circ}$ Compreende-se por guarda unilateral a atribuída a um só dos genitores ou a alguém que o substitua (art. 1.584, § 5ㅇ) e, por guarda compartilhada, a responsabilização conjunta e o exercício de direitos e deveres do pai e da mãe, que não vivam sob o mesmo teto, concernentes ao poder familiar dos filhos comuns.
}

De acordo com essa legislação, ambos os pais assumem a responsabilidade de garantir o bem estar do filho e de assegurar os direitos fundamentais ao desenvolvimento dos descendentes.

Com estas alterações no Código Civil, aos Juízes das áreas de família competem, preferencialmente, propor aos genitores a co-responsabilidade em relação aos filhos e a contínua participação na vida destes após a separação (GOIS, 2008).

Desde então, este assunto está sendo amplamente discutido na mídia (impressa, televisiva e eletrônica) partindo de vários questionamentos, tais como: Com quem a criança irá morar? Há necessidade de a criança ficar cada dia da semana em uma casa? Como serão tomadas as decisões se o pai e a mãe não chegarem a um acordo? O pai fica desobrigado de pagar pensão? Quem ficará responsável pelas despesas do filho? Será que a equipe técnica do judiciário participará dessas decisões? Como os técnicos do judiciário irão trabalhar com a guarda compartilhada?

Tais discussões despertaram o interesse em realizar uma pesquisa sobre essa temática. Logo, observou-se que os estudos já desempenhados nessa linha abordavam, em sua grande maioria, a perspectiva dos pais.

Então, tendo em vista que "ao se avaliar a adoção de qualquer modalidade de guarda de filhos, é imperioso ter como regra norteadora o princípio do melhor interesse da criança e do adolescente" (LIMA, 2006, p. 24), estudar a guarda compartilhada 
pressupõe considerar as reais necessidades desses sujeitos, ainda em condição de desenvolvimento pessoal, biológico e social.

Outro ponto que motiva o estudo da guarda compartilhada é o exercício profissional de uma das pesquisadoras como assistente social judicial. Dentre os princípios fundamentais da ética profissional do assistente social está a defesa intransigente dos direitos humanos e compromisso com a qualidade dos serviços prestados (CONSELHO FEDERAL DE SERVIÇO SOCIAL, 1997). Dessa forma, este estudo é fundamental para assegurar o compromisso com a garantia do respeito às especificidades da criança e do adolescente em processos judiciais que envolvam guarda dos filhos.

Reportamos também ao tal trabalho no intuito de aferir teoricamente a relação da guarda compartilhada com o dever das famílias em assegurar, com absoluta prioridade, o direito à convivência familiar e comunitária de seus descendentes, imposto expressamente no artigo 227 da Constituição Federal de 1988 (BRASIL, 1988).

Tem-se também a intenção de estudar como a Lei № 11.698/2008 se relaciona com o exercício do poder familiar, conforme demanda o Estatuto da Criança e do Adolescente (BRASIL, 1990) em seu artigo 21: "O pátrio poder será exercido, em igualdade de condições, pelo pai e pela mãe, na forma do que dispuser a legislação civil, assegurando a qualquer deles o direito de, em caso de discordância, recorrer à autoridade judiciária competente para a solução da divergência".

Ainda neste sentido, o ECA postula, em seu artigo 22, que "aos pais incumbe o dever de sustento, guarda e educação dos filhos menores, cabendo-Ihes ainda, no interesse destes, a obrigação de cumprir e fazer cumprir as determinações judiciais".

Concomitantemente, pretende-se compreender a relação da guarda compartilhada com o dever da família em assegurar com absoluta prioridade a efetivação dos direitos referentes à vida, à saúde, à alimentação, ao esporte, ao lazer, à profissionalização, à cultura, à dignidade, ao respeito e à liberdade, conforme artigo 4으 do ECA.

Portanto, o trabalho propõe compreender o que está previsto na Lei № 11.698/2008, em convergência com as demais legislações que tratam dos direitos das crianças e dos adolescentes. 


\section{Metodologia}

De acordo com Minayo \& Sanches (1993), o conhecimento científico é sempre uma busca de articulação entre a teoria e a realidade empírica; assim sendo, o método utilizado durante a pesquisa é o caminho para alcançar esta articulação.

Neste trabalho, para se chegar aos objetivos propostos, foi realizada uma pesquisa com abordagem qualitativa. Para Minayo (2002), a pesquisa qualitativa se preocupa, nas ciências sociais, com "um nível de realidade que não pode ser quantificado, trabalha com um universo de significados, aspirações, crenças, valores e atitudes, o que corresponde a um espaço mais profundo das relações." (MINAYO, 2002, p. 21)

Isso, através do Método Dedutivo, que aproveita as teorias já existentes comparando-as e aperfeiçoando-as, associado ao Método Bibliográfico, que faz comparações de todas as teorias e práticas sobre o assunto a ser estudado (BRUGGER, 1962).

Para a execução de tal método, as investigações sobre o assunto procederam via levantamento de bibliografia, de consultas à Internet e da legislação sobre o tema guarda compartilhada, concomitante à leitura e fichamento do material de acervo teórico.

Após tais procedimentos, houve avaliação das informações obtidas, com reflexões do que foi estudado no intuito de construir as considerações finais.

\section{Os aspectos legais da guarda compartilhada}

Estudando a legislação que rege o tema proposto, verifica-se que o princípio geral a ser acatado é o de que crianças e adolescentes devem ser considerados como sujeitos de Direitos, que carecem de proteção integral, haja vista estarem em condição peculiar de desenvolvimento biológico, psicológico e social.

Pode-se afirmar, via de regra, que os pais são os responsáveis e maiores interessados por este desenvolvimento, além da criação, formação e proteção dos filhos menores de 18 anos de idade.

Relacionando a proteção integral à criança e ao adolescente com a história da legislação brasileira pode-se mencionar que o Direito de Família Brasileiro sofre influências do Direito Romano e do Cristianismo. A partir disso, o Código Civil de 1916 
prescrevia que o matrimônio era o assento básico para a formação da família e era indissolúvel. Sendo assim, o direito deveria ocupar-se basicamente das relações familiares que compreendiam o casamento e o pátrio poder - atualmente poder familiar. (ALVES, 2005)

Alves (2005) elucida que este modelo de família romano que influenciou a família ocidental se caracteriza por sua rigidez patriarcal e relativa autonomia em relação ao Estado, ou seja, o Estado Romano não interferia nas questões surgidas no seio da família. De tal modo, o poder familiar ficava restrito ao pater familias, figura principal da família romana, chefe absoluto, que detinha todos os poderes sobre os integrantes da família e ainda sobre a manutenção do grupo familiar.

As legislações posteriores ${ }^{1}$, gradativamente, mudaram a concepção de família, chegando a reconhecer a união estável entre homem e mulher e a comunidade formada por qualquer um dos pais e seus descendentes como entidade familiar.

Neste sentido, a CF trouxe inúmeras e relevantes inovações na concepção de estrutura familiar. Com o advento desta constituição a sociedade passa a ter uma legislação que observa a família partindo das idéias de igualdade, afetividade e, sobretudo, da dignidade da pessoa humana. Assim, no direito de família houve grandes mudanças, "passando-se de uma sociedade patriarcal, matrimonializada e hierarquizada para a valorização do afeto como fundamento da proteção às instituições familiares" (SIMÃO, 2005, p. 33).

A CF em seu artigo 5o presume a igualdade absoluta entre mulheres e homens. Ainda neste sentido, o artigo 226 , §5으, da mesma legislação prevê a igualdade entre a figura masculina e feminina em relação aos direitos intrínsecos à vida conjugal. Com esse princípio modifica-se o poder marital e a vinculação da figura feminina às tarefas domésticas e à procriação. A partir de então, as decisões relativas à família, destacando a responsabilização pelos filhos, devem ser tomadas de comum acordo entre ambos os genitores.

O artigo 227 da CF prescreve que toda criança e adolescente tem o direito de viver em família, seja ela natural ou substituta. Isso não diz respeito só à mãe e ao pai, mas a

\footnotetext{
${ }^{1}$ Por exemplo: a Lei № 5.869/1973 (Código do Processo Civil), a Lei № 6.515/1977 (regula os casos de dissolução conjugal e do casamento), Lei № 10.406/2002 (Código Civil), ECA e CF.
} 
irmãos, tios, avós e demais membros da família ${ }^{2}$. Concomitantemente, o reconhecimento deste direito requer a proteção da família, independente de sua composição, pois a criança e o adolescente devem sentir-se protegidos, confortados, respeitados e gozar de todos os direitos fundamentais e essenciais à sua formação como ser humano.

Esses sujeitos, em condição de desenvolvimento, não são e não podem ser tratados como objetos na disputa por pais ou familiares. Ademais, nem estarem vivenciando constantemente e eternamente conflitos entre os pais, uma vez que esta experiência poderá acarretar transtornos psicológicos irreversíveis em suas vidas ${ }^{3}$ (ALVES, 2005).

O ECA tem origem no artigo $227^{4}$ da Constituição da República Federativa do Brasil de 1988 , sendo a legislação que ressalta a doutrina do melhor interesse da criança e do adolescente. De tal modo, esse princípio é regra a ser observada, obrigatoriamente, nas questões paterno-filiais.

O artigo 4으 do ECA estabelece que um dos deveres da família é assegurar aos sujeitos em condição de desenvolvimento a convivência familiar e comunitária, posto que

A responsabilidade da família, universalmente reconhecida como um dever moral decorre da consangüinidade e do fato de ser o primeiro ambiente em que a criança toma contato com a vida social. Além disso, pela proximidade física, que geralmente se mantém, é a família quem, em primeiro lugar, pode conhecer as necessidades, deficiências e possibilidades da criança, estando, assim, apta a dar primeira proteção. Também, em relação ao adolescente, é na família, como regra geral, que ele tem maior intimidade e a possibilidade de

\footnotetext{
${ }^{2}$ Vetada a permanência prolongada de crianças e adolescentes em instituições - abrigos.

${ }^{3}$ No século XIX surge o modelo de Família Burguesa caracterizando a figura materna como a responsável pelos cuidados e educação dos filhos e a figura paterna como provedora do sustento do núcleo familiar. Com a Revolução Industrial, aparece o modelo de Família da Classe Trabalhadora em que todos os membros da família trabalhavam em fábricas. O modelo de Família Contemporânea (séculos XX e XXI) é oriundo da Família Burguesa; assim, a mulher está inserida no mercado de trabalho, mas continua fortemente relacionada aos cuidados da casa e, sobretudo dos filhos. Por decorrência desta cultura da família burguesa que associa o amor materno às funções biológicas, nos casos da guarda unilateral, normalmente a genitora assume o exercício das funções de guardião (FIDOMANZO, 2008). Pois, a "... justiça tem tratado a questão dos filhos na separação de casais baseando-se, em geral, em preconceitos e teorias ultrapassadas [...] não considerando a evolução da mulher e do homem nos últimos anos [...]" (PARENTE, 2008, p.1). Neste diapasão, torna-se imprescindível reconhecer que o afeto e afinidade são construídos, tanto em homens e mulheres, a partir da convivência com os filhos; e, na ocorrência dos conflitos relacionados à guarda dos filhos é preciso que a mulher do século XXI, “[...] guiada pelos valores capitalistas e pelo direito de conquistar sua independência e seu espaço, não lhe retire a sensibilidade para avaliar e respeitar o direito do homem com relação aos filhos e nem torná-los reféns de seus caprichos e do seu "pseudo-poder", para não passar de oprimida à opressora (FIDOMANZO, 2008, p. 2-3).

4 “Art. 227-É dever da família, da sociedade e do Estado assegurar à criança e ao adolescente, com absoluta prioridade, o direito à vida, à saúde, à alimentação, à educação, ao lazer, à profissionalização, à cultura, à dignidade, ao respeito, à liberdade à conivência familiar e comunitária, além de colocá-los a salvo de toda forma de negligência, discriminação, exploração, violência, crueldade e opressão".
} 
revelar mais rapidamente suas deficiências e as agressões e as ameaças que estiver sofrendo. (CURY, 2006, p. 38).

A família é conceituada no artigo 25 do ECA como a comunidade formada pelos pais, ou por um deles e seus descendentes. De tal modo, observa-se uma grande mudança na concepção sobre a guarda: passa-se a compreender que a criança pode e deve conviver com o pai e a mãe, mesmo que estes não formem um casal (BRITO, 2001, p. 9).

Ambos os pais podem exercer o poder familiar, em igualdade de condições (ECA, artigo 21), pois o entendimento é de que a obrigação de educar e cuidar dos filhos é decorrente do vínculo de filiação e não do casamento. Corrobora-se que ao pai e à mãe não há que delegar competências ou encargos diferenciados, tão somente por serem de sexos diferentes (NOVAES, 2005, p. 54).

Ressalta-se que os pais não podem renunciar ao exercício dos encargos compartilhados na forma da lei, já que a eles incumbe o dever de sustento, guarda e educação dos filhos menores de 18 anos, cabendo-lhes ainda, no interesse destes, a obrigação de cumprir e fazer cumprir as determinações judiciais, conforme o artigo 22 do ECA.

Os pais têm o dever de sustento, guarda e educação dos filhos menores, e a obrigação de cumprir e fazer cumprir as determinações judiciais no interesse da criança e do adolescente. Tais deveres estão relacionados aos direitos fundamentais dos menores de 18 anos de idade, sobretudo, no direito à convivência familiar e comunitária.

Caso um dos pais abuse do seu poder, falte com os deveres paternos/ maternos, arruínem os bens dos filhos e/ou se mostrem negligentes em garantir os direitos fundamentais dos filhos, pode ocorrer a perda ou a suspensão do poder familiar. Para isso, compete ao Juiz de Direito, após o requerimento de algum familiar ou representante do Ministério Público, adotar a medida que vá ao encontro dos interesses da criança e do adolescente.

Faz-se necessário mencionar que a destituição do poder familiar pode ocorrer em desfavor de um ou dos dois genitores.

Destaca-se que a privação material não pode ser confundida com 0 descumprimento dos deveres aludidos no artigo 22 do ECA. Registra-se que o artigo 24 do 
ECA estabelece que nos casos dos genitores serem carentes de recursos materiais, o Estado está obrigado a protegê-los e assisti-los, enquanto família, para que cumpram seus deveres.

No ECA o instituto que regulamenta a posse da criança e do adolescente é definido como guarda. Este instituto pode ser exercido pelos genitores, por integrantes da família extensa e por pessoas que não pertencem à família dos menores de 18 anos.

A guarda obriga à prestação de assistência material, moral e educacional à criança ou adolescente e confere ao seu detentor o direito de opor-se a terceiros, inclusive aos pais (ECA, 1990, artigo 33). Esse instrumento jurídico pode ser aplicado conforme a peculiaridade do caso e a decisão do Juiz de Direito pode ser de forma definitiva ou provisória. A guarda provisória é definida até que sejam tomadas as medidas adequadas para a defesa dos interesses da criança e do adolescente. A guarda definitiva regulariza a posse de fato da criança e do adolescente e pode ser deferida de tutela e adoção.

Além disso, a guarda é instrumento utilizado como medida de proteção dos direitos da criança e do adolescente que pode ser modificado a qualquer momento mediante ato judicial.

Destaca-se prioritariamente, que a criança e o adolescente devem conviver no seio da família natural, preferencialmente com ambos os pais.

Para resguardar esse direito à convivência com ambos os genitores destaca-se o instituto da guarda compartilhada, que tem dentre seus objetivos a possibilidade de convívio frequente das crianças e dos adolescentes com os pais. Esta convivência pode ocorrer em casos que os pais estão separados conjugalmente ou não chegaram a estabelecer nenhum tipo de união.

A guarda compartilhada refere-se a uma modalidade onde os pais e mães dividem a responsabilidade legal sobre os filhos ao mesmo tempo e compartilham as obrigações pelas decisões relativas aos descendentes menores de 18 anos (PEREZ, 2005).

Neste contexto, pode-se afirmar que a Lei 8.069/1990 abarca matérias do Direito Civil, na perspectiva do Direito de Família. Todavia, convém mencionar que

Como as principais relações jurídicas entre o mundo infanto-juvenil e o mundo adulto encontram-se disciplinadas no microssistema criado pelo Estatuto da Criança e do Adolescente, a elas são aplicáveis as normas nele previstas. 
Somente devem incidir as normas do Código Civil [...] quando houver lacuna no Estatuto da Criança e do Adolescente, e mesmo assim se não forem incompatíveis com seus princípios fundamentais (JUNIOR, N. N. \& MACHADO, J. D. T., 2002, p. 14).

O Código Civil vigente foi promulgado em 2002, sob a Lei № 10.406 . Neste regulamento a situação da criança e do adolescente em relação aos genitores é exaltada na questão do poder familiar. Convém mencionar que o poder familiar

pode ser definido como um conjunto de direitos e obrigações, quanto à pessoa do filho menor não emancipado, exercido em igualdade de condição, por ambos os pais, para que possam desempenhar os encargos que a norma jurídica Ihes impõe, tendo em vista o interesse e a proteção do filho (DINIZ, 2004, p. 348).

Assim sendo, enquanto os genitores estão casados, em união estável ou estabelecendo outras formas de relacionamento, Ihes competem o exercício desse poder que é a soma de deveres. Neste tocante, conforme o artigo 1631 do Código Civil, na falta de um dos pais ou, até mesmo em caso de impedimento de um deles, ao outro se incumbe o desempenho do encargo em caráter exclusivo.

Depreende-se deste contexto que, em ocorrências de divergências entre os genitores, há possibilidade de que qualquer uma das partes (pai ou mãe) recorra ao Juiz de Direito para a solução dos desacordos.

Os desacertos entre os genitores podem culminar na dissolução da sociedade conjugal por meio da separação judicial, na extinção do casamento pelo divórcio e na dissolução da união estável entre os conviventes (BRASIL, 2002). Entretanto, as partes permanecerão usufruindo os direitos e deveres inerentes ao poder familiar, exceto, logicamente, nos casos que houver impedimentos judiciais.

O artigo 1633 desta legislação reza que no caso de crianças e adolescentes que não tiveram a paternidade reconhecida, o exercício do poder familiar é exclusivo da genitora, se for conhecida e estiver em condições de desempenhar tal atribuição.

O Código Civil em seu artigo 1634 estabelece que

Compete aos pais, quanto à pessoa dos filhos menores:

I - dirigir-Ihes a criação e educação;

II - tê-los em sua companhia e guarda;

III - conceder-Ihes ou negar-lhes consentimento para casarem;

IV - nomear-Ihes tutor por testamento ou documento autêntico, se o outro dos pais não lhe sobreviver, ou o sobrevivo não puder exercer o poder familiar; 


\begin{abstract}
V - representá-los, até aos dezesseis anos, nos atos da vida civil, e assisti-los, após essa idade, nos atos em que forem partes, suprindo-lhes o consentimento; VI - reclamá-los de quem ilegalmente os detenha;

VII - exigir que lhes prestem obediência, respeito e os serviços próprios de sua idade e condição.
\end{abstract}

Mediante o exposto na citação acima, verifica-se que ambos os genitores têm o direito e o dever de ter os filhos em sua guarda e companhia, tendo em vista que para executar as demais funções inerentes ao poder familiar faz-se necessário tê-los consigo, sobretudo, para orientá-los na formação moral e intelectual.

Forçoso observar que caso ocorra dissolução da sociedade ou do vínculo conjugal pela separação judicial por mútuo consentimento ou pelo divórcio direto consensual, observar-se-á o que os cônjuges acordarem sobre a guarda dos filhos (BRASIL, 2002). Porém, ressalta-se que este acerto não pode acarretar prejuízo ou danos ao desenvolvimento biológico, psicológico e social da criança e/ ou do adolescente.

A Lei № 11.698/2008 que dispõe sobre o instituto da guarda compartilhada traz alterações nos artigos 1.583 e 1.584 do Código Civil para respaldar as decisões judiciais nas Varas de Família. A partir desta legislação, o Juiz de Direito deve propor aos pais a guarda compartilhada, em todas as ações referentes à separação e/ou, especificamente, à guarda; considerando que além do direito de participar da vida filhos, pai e mãe passam a ter o dever de fazê-lo.

Depreende-se deste ordenamento legal que não há motivo para confiar a guarda apenas a um dos pais, quando ambos têm condições de exercê-la e quando os filhos necessitam destes cuidados para se desenvolverem emocionalmente (SILVA, 2005).

Então, durante a realização das audiências, cabe ao Juiz de Direito esclarecer às partes envolvidas no caso a necessidade de estabelecerem uma relação de respeito mútuo, ressaltando a necessidade de garantir o melhor interesse da criança ou adolescente, pois a guarda compartilhada só pode ser aplicada judicialmente se houver entendimento entre os pais.

Ilustra-se também que esta modalidade de guarda pode ser requerida pelo pai ou pela mãe, ficando a cargo do juiz a avaliação para que a medida seja aplicada. 
Destaca-se que neste tipo de guarda os pais precisam estabelecer acordos referentes ao local de habitação da criança ou adolescente, à educação (formação pessoal e vida escolar) e à participação econômica.

Nos casos em que os pais não conseguem combinar seus exercícios parentais a favor do filho, o Juiz de Direito pode decidir com bases nas peculiaridades do caso concreto. Além do exposto, o Juiz de Direito pode determinar à Equipe Técnica (Assistente Social e Psicólogo) que realizem um estudo sobre o caso.

Durante a intervenção familiar cabe à Equipe Técnica ressalvar a proteção integral dos direitos da criança e do adolescente, considerando que

[...] a guarda compartilhada só é possível quando o ambiente familiar pósseparação ou pós-divórcio é propício ao diálogo e à participação igualitária de ambos os pais [...]. Do contrário, o exercício parental por parte do não detentor da guarda restringe-se a uma atuação distante e meramente fiscalizadora (LIMA, 2006, p. 23).

Convém mencionar que a Equipe Técnica inserida no Tribunal de Justiça emite avaliações do caso a partir da realidade social (composição familiar, condições de habitação, grau de instrução, condições de trabalho, inserção em programas assistenciais, participação na vida comunitária, qualidade nas relações intra-familiares e extrafamiliares, indicativos de capacidade de proteção aos filhos, dentre outros aspectos intrínsecos à questão social) e estudo psicológico dos envolvidos (relações intrafamiliares/ afinidade/ afetividade). Ademais, os integrantes da Equipe Técnica relevam as opiniões de crianças e adolescentes, em vista dos vínculos que estabelecem com cada um dos genitores (FÁVERO; MELÃO; JORGE, 2005).

Compete ainda aos técnicos do Serviço Social e da Psicologia intervir nos procedimentos de guarda e ou separação, provocando reflexões nos genitores que favoreçam o desenvolvimento das relações familiares e a convivência familiar.

Mister descrever neste trabalho, objetivando o estabelecimento de acordos duráveis em prol dos direitos dos filhos, uma das modalidades de intervenção utilizadas por Equipes Técnicas do Judiciário é a Mediação ${ }^{5}$. Ganancia $(2001$, p. 8) define que

\footnotetext{
5 “[...] a mediação familiar [...] surgiu nos EUA por volta de 1974, e teve como objetivo prevenir os danos produzidos pelo divórcio, e sobretudo as suas conseqüências negativas no desenvolvimento dos filhos. Fiel a estes objetivos iniciais, a mediação familiar, sobretudo, tem por objeto a família em crise, quando
} 
Mediação familiar é um procedimento estruturado de gestão de conflitos, pelo qual a intervenção confidencial e imparcial de um profissional qualificado, o mediador, visa a restabelecer a comunicação e o diálogo entre as partes. Seu papel é o de levá-los a elaborar, por eles próprios, acordos duráveis que levem em conta as necessidades de cada um e em particular, das crianças em um espírito de co-responsabilidade parental.

A técnica da mediação propõe mudanças culturais na forma de enfrentar o conflito, leva as partes a reconhecerem suas diferenças, possibilitando-as de encontrar soluções viáveis, para alcançar a satisfação dos interesses envolvidos no processo em questão (VILELA, 2008).

\section{Os aspectos práticos da guarda compartilhada}

A guarda compartilhada é um chamado aos pais que vivem separados para exercerem em conjunto os cuidados com os filhos e, neste sentido, um dos genitores pode até mesmo deter guarda material ou física do filho - coabitar com esta criança ou adolescente. Ocorre, todavia, que o pai e a mãe precisam repartir os deveres e os direitos inerentes ao poder familiar, haja vista que concorre concomitantemente aos genitores definir sobre a educação, religião, cuidados com a saúde, lazer, estudos, enfim, em tudo na vida do filho.

É importante elucidar que a criança ou adolescente que tem sua guarda compartilhada não mora metade da semana na casa do pai e a outra metade na casa da mãe $e^{6}$. Os contatos entre pais, mães e filhos acontecem de forma natural, de acordo com a saudade que o descendente tem dos genitores e vice-versa. Trata-se da possibilidade de um convívio amplo, fundamentado na comunicação e informalidade, que proporciona a

seus membros se tornam vulneráveis, não para invadir ou para dirigir o conflito, mas para oferecer-Ihes uma estrutura de apoio profissional, a fim de que lhes seja aberta a possibilidade de desenvolverem, através das confrontações, a consciência de seus direitos e deveres, criando condições para que o conflito seja resolvido com o mínimo de comprometimento da estrutura psico-afetiva de seus integrantes, podendo também ser vista como uma técnica eficiente para desobstruir os trabalhos nas varas de família e nas de sucessões, influindo decisivamente para que as querelas judiciais tenham uma solução mais fácil, rápida e menos onerosa" (DANTAS, 2008, p. 1).

${ }^{6}$ Os casos em que os filhos permanecem alguns dias da semana na casa da genitora e outros dias na casa do genitor estão dentro da modalidade de Guarda Alternada. Neste tipo de guarda um dos genitores exerce, alternadamente, a guarda dos filhos. A grande desvantagem desse sistema é a não determinação de um domicílio definitivo para a criança o que pode gerar problemas na formação da sua personalidade, não havendo um ponto fixo de referência para se direcionar ou se apoiar, priorizando tão somente a convivência com os pais. (PEREZ, 2005, p. 6) 
preservação dos laços afetivos entre pais e filhos. Este estreitamento de vínculos visa o bem estar dos filhos (LIMA, 2006).

Nestas situações, a criança ou o adolescente tem capacidade de se adaptar ao contexto de vida dos genitores, além de conseguir criar vínculo com a casa do pai e com a casa da mãe. Em relação a este objeto, Silva (2008, p. 2) entende que

Permitir à criança o convívio com pai e mãe, vai deixá-la segura, e o medo do abandono não terá espaço, resultando em crianças que se adaptarão bem a situações novas, que poderão lidar com frustrações e limites. Torna-se imprescindível que ela se adapte com o fato de ter duas casas, pois esta é a realidade posta: seus pais têm cada um a sua casa, e continuam sendo seus pais. Logo, ela tem duas casas.

Referente ao pagamento da pensão alimentícia, na guarda compartilhada os pais acordam em dividir as despesas com os filhos e em assumirem a co-responsabilidade pelo sustento material destes filhos, mediante acordo. Pode-se, por exemplo, citar que por meio de combinações, a mãe fica responsável pelo pagamento do transporte e planos de saúde, enquanto ao pai resta o pagamento das despesas escolares e farmácia.

Nesse tocante de equidade para com as despesas, faz-se indispensável que os pais sejam sensíveis às necessidades dos filhos.

Frise-se também que a continuidade do convívio da criança ou do adolescente com ambos os pais é indispensável para a formação pessoal e social. Tendo em vista que

\footnotetext{
O Poder/Dever de educar, compreendendo os vários aspectos de socialização da criança e do adolescente, quer dizer do processo pelo qual, se lhe permite adquirir, em harmonia com as inclinações e aptidões de cada um, as atitudes, normas de comportamento, e conhecimentos indispensáveis, para o seu desenvolvimento físico, intelectual e moral, de forma livre e crítica. Uma vida social integrada torna indispensável o compartilhamento pelos pais dos deveres inerentes à guarda, em co-responsabilidade convergente, entendida e solidária, de molde a contribuir decisivamente para o pleno desenvolvimento de seus filhos (AZEVEDO, 2001, p. 4).
}

Enfim, é salutar para esses sujeitos em condição de desenvolvimento pessoal e social sentir cotidianamente a participação dos pais em sua formação e educação. Todavia, a aplicabilidade e o adequado exercício da guarda compartilhada depende da realidade social de cada família e do estado emocional do envolvidos (filhos/ mãe/ pai). 


\section{Considerações finais}

Através das legislações estudadas e dos referenciais teóricos pesquisados que abordam prioritariamente a temática guarda compartilhada foi possível aferir que essa modalidade de guarda é a expressão do direito à convivência familiar. Não obstante, a guarda compartilhada demonstra a oportuna valorização dos bens que os sentimentos de afeto e afinidade podem oferecer ao integral desenvolvimento da criança e/ ou adolescente.

Assim, forçoso é admitir que, a modalidade de guarda compartilhada com princípio de participação cotidiana dos genitores na vida dos filhos e divisão de responsabilidades em relação aos mesmos, vai ao encontro do atendimento aos direitos fundamentais dos filhos menores de 18 anos.

Por óbvio, a aplicabilidade da modalidade de guarda estudada neste trabalho pressupõe que os genitores elevem os interesses dos filhos acima de seus próprios e das dificuldades emergidas no contexto do litígio, além de conseguirem uma convivência minimamente boa, haja vista que os fundamentos da guarda compartilhada são os acordos que podem ser estabelecidos entre os pais em prol da educação (formal/ formação pessoal), do sustento e do local de habitação dos filhos. Assim sendo, os genitores conseguem proteger o exercício das funções de pai e mãe e dividirem as responsabilidades em relação aos filhos.

Nos casos em que os pais não conseguem estabelecer consensos acerca dos descendentes, cabe ao Juiz de Direito decidir, com bases nas peculiaridades de cada caso concreto, a determinação da guarda compartilhada ou unilateral.

Para fundamentar tal decisão, o Juiz de Direito pode solicitar à Equipe Técnica do Fórum, geralmente constituída por assistentes sociais e psicólogos, que realizem um estudo sobre o núcleo familiar. Tal intervenção técnica tem em vista a realidade social da família e o estado psicológico dos integrantes do grupo familiar.

Destaca-se ainda como competência da equipe técnica que atua com famílias em situação de litígio e/ ou processos de guarda estabelecer com os genitores reflexões sobre o exercício das funções paternais, do poder familiar, da importância de participarem cotidianamente da formação dos filhos, dentre outras que favoreçam o estabelecimento das relações familiares. 
Destarte, a aplicação da guarda compartilhada, preservando a proteção integral dos direitos da criança e do adolescente, depende da realidade sócio familiar de cada caso e do estado emocional dos envolvidos (filhos/ mãe/ pais).

Ressalta-se que esta pesquisa não pretendeu esgotar o assunto, visto que a produção de conhecimento é um processo constante e cumulativo. O conhecimento apreendido com esta pesquisa possibilitou uma apropriação do assunto para um melhor exercício profissional e ressalvou a necessidade de considerar a realidade específica de cada caso para a preservação do princípio de melhor interesse da criança e/ ou do adolescente.

\section{Referências}

ALVES. J. F. Regime de Visitas: reforma processual exige acordo de visitas aos filhos. Revista Jurídica Consulex. São Paulo, ano 9,. N. 203, p. 52-53, jun.2005.

AZEVEDO, Maria Raimunda Teixeira de. A guarda compartilhada. Discurso apresentado a Comissão Permanente das Mulheres Advogadas da OAB/ RJ. Rio de Janeiro, 2001. Disponível em <http:www.apase.org.br>. Acesso em 13 ago. 2008.

BRASIL. [Constituição 1988]. Constituição da República Federativa do Brasil. São Paulo: Revistas dos Tribunais, 1988.

.Estatuto da Criança e do Adolescente (ECA): Lei Federal 8069/1990. Brasília, 1990.

Lei № 10.406/2002, de 10 de janeiro de 2002. Código Civil. Disponível em: <http: www.gabinetecivil.goias.gov.br/leis_ordinarias/1986/lei_10106.htm-5k->. Acesso em: 29 jun. 2008.

.Lei № 11.698/2008, de 13 de junho de 2008. Disponível em <http:www.planalto.gov.br/ccivl_03/_ato2007-2010/2008/lei_11698.htm-1k->. Acesso em: 29 jun. 2008.

BRITO. L. M. T. Impasses na condição da guarda e da visitação: o palco da discórdia. Disponível em: <http:www.apase.org.br>. Acesso em: 15 ago. 2008.

BRUGGER, W. Dicionário de filosofia. São Paulo: Herder, 1962.

CONSELHO FEDERAL DE SERVIÇO SOCIAL. Código de ética profissional do assistente social e Lei 8.662/93 de regulamentação da profissão. 3. ed. Brasília: CFESS, 1997. 
CURY. M.; SILVA, A. F. A.; MENDES, E. G. (Coord.). Estatuto da Criança e do Adolescente. Lei 8.069/1990: comentários jurídicos e sociais. 8. ed. São Paulo: Malheiros, 2006.

DANTAS. A. F. A mediação familiar e sua aplicação nas áreas de família. Disponível em: <http:www.apase.org.br>. Acesso em: 26 dez. 2008.

DINIZ, Maria Helena. Direito de Família. Curso de direito civil brasileiro. 17. ed. São Paulo: Saraiva, 2004. v.2.

FÁVERO. E. T.; MELÃO. M. J. R.; TOLOSA. M. R. O Serviço social e a psicologia no judiciário: construindo direitos. 2. ed. São Paulo: Cortez, 2005.

FIDOMANZO. M. C. L. A guarda compartilhada sempre existiu. Disponível em: <http:www.apase.org.br>. Acesso em: 11 set. 2008.

GANACIA. D. F. Mediação Familiar. Revista da Associação dos Advogados de São Paulo, São Paulo, n. 62, p.7-15, 2001.

GOIS, C. Lula sanciona projeto de lei da guarda compartilhada de filho de pais separados. O Globo. Disponível em:

<http:www.oglobo.com/pais/mat/2008/06/13/lula_sanciona_projeto_ de_lei_da_guarda_compartilhada_de_filhos_de_pais_separados-546788223.asp $>$. Acesso em: 29 jun. 2008.

JÚNIOR, N. N.; MACHADO, J. T. O Estatuto da Criança e do Adolescente e o novo Código Civil à luz da Constituição Federal: princípio da especialidade e Direito Intertemporal. Revista de Direito Privado, São Paulo, ano 3, p.12-49, out./dez. 2002.

LIMA, S. B. V. Guarda compartilhada: aspectos teóricos e práticos. Revista CEJ, Brasília, n. 34, p.22-26, jul./set. 2006.

MINAYO, M.C.S. (Org.) Pesquisa social: teoria, método e criatividade. 20. ed. Petrópolis: Vozes, 2002.

MINAYO, M. C. S.; SANCHES, O. Quantitativo-Qualitativo: oposição ou complementaridade? Cadernos de Saúde Pública, Rio de Janeiro, v. 9, n. 3, p. 239-262, jul./set. 1993.

NOVAES, E. M. A incapacidade civil dos pais é causa de extinção do poder familiar? Revista Jurídica Consulex, São Paulo, ano 9, n. 2085, p.54-55, 15 set. 2005.

PARENTE. J. I. Sobre a guarda compartilhada. Disponível em: <http:www.apase.org.br>. Acesso em: 11 set. 2008.

PEREZ. S. C. Guarda compartilhada: sob o enfoque do melhor interesse do menor. 2005. Trabalho de Conclusão de Curso (Graduação em Direito) - Centro Universitário Eurípedes de Marília, Marília.. 
SILVA, E. L. A separação do casal e as conseqüencias deste tipo de guarda na vida dos filhos. Disponível em: <http:www.apase.org.br>. Acesso em: 15 ago.2008.

SILVA. E. L. Guarda de filhos: aspectos psicológicos. In: ASSOCIAÇÃO DE PAIS E MÃES SEPARADOS (Org.). Guarda compartilhada: aspectos psicológicos e jurídicos. Porto Alegre: Editora Equilíbrio, 2005. p.13-31.

SIMÃO. R. B. C. O Abuso de direito no exercício do poder familiar. In: ASSOCIAÇÃO DE PAIS E MÃES SEPARADOS (Org.). Guarda compartilhada: aspectos psicológicos e jurídicos. Porto Alegre: Editora Equilíbrio, 2005. p.33-51.

VILELA. S. R. Meios alternativos guarda compartilhada: pelo fim da mãe déspota. Disponível em: <http:www.apase.org.br>. Acesso em: 26 dez.2008. 